\title{
Implications of fidelity and philopatry for the population structure of female black-tailed deer
}

\author{
Samhita Bose, ${ }^{a}$ Tavis D. Forrester, Jennifer L. Brazeal,c Benjamin N. Sacks, ${ }^{c, d}$ \\ David S. Casady, and Heiko U. Wittmer ${ }^{\mathrm{e}, \mathrm{b}}$ \\ aSchool of Biological Sciences, Victoria University of Wellington, PO Box 600, Wellington 6140, New \\ Zealand, bDepartment of Wildlife, Fish and Conservation Biology, University of California at Davis, \\ 1 Shields Avenue, Davis, CA 95616, USA, cMammalian Ecology and Conservation Unit, Veterinary \\ Genetics Laboratory, University of California at Davis, 1 Shields Avenue, Davis, CA 95616, USA, \\ dDepartment of Population Health and Reproduction, School of Veterinary Medicine, University of

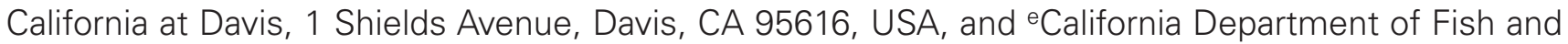 \\ Wildlife, Large Mammal Conservation Program, 1812 9th Street, Sacramento, CA 95811, USA
}

Received 23 June 2016; revised 30 January 2017; editorial decision 1 February 2017; accepted 7 March 2017.

Site fidelity and philopatry are behavioral adaptations found in many species and their fitness benefits are well documented. The combined population level consequences of site fidelity and philopatry, however, have received little attention despite their importance for understanding spatial patterns in connectivity and population dynamics. We used an integrative approach to explore consequences of fidelity and philopatry on the fine-scale genetic structure of black-tailed deer (Odocoileus hemionus columbianus). We assessed fidelity to seasonal home ranges based on location data from 64 female deer fitted with global positioning system (GPS) collars between 2004 and 2013. We assessed philopatry from mitochondrial DNA (mtDNA) haplotypes using DNA extracted from 48 deer. Results based on location data revealed very small movements and seasonal home ranges together with high site fidelity. Fidelity improved survival; every $1 \mathrm{~km}$ increase in mean interlocation distances between consecutive summers increased the risk of mortality by $56.5 \%$. Results from mtDNA sequencing revealed high genetic differentiation $\left(F_{\mathrm{ST}}>0.30\right)$ and low haplotype sharing among geographic areas separated by as little as $4-10 \mathrm{~km}$. The high genetic differentiation indicated multigenerational periods of philopatric behavior in the matrilineage of black-tailed deer. Combined these results suggest that site fidelity together with strong sex-biased philopatry can create marked short- and long-term demographic isolation and trap matriarchal units as a subset of the larger population with locally determined vital rates. Where such fine-scale population structuring as a consequence of fidelity and philopatry occurs, matrilineal groups might in some cases best serve as the basic units of conservation and management.

Key words: animal movements, cervids, familiarity, population dynamics, predation, site fidelity, social organization, survival

\section{INTRODUCTION}

Animal populations are naturally predisposed to spatial structuring due to the generally nonrandom and clumped distribution of resources (Turner 1989). The degree of structuring varies among species and depends on life-history traits, social organization, ecological requirements, and mobility (e.g., Clutton-Brock and Coulson 2002; Coltman et al. 2003; Nussey et al. 2005). Highly mobile species are expected to show little spatial structuring at fine

Address correspondence to H.U. Wittmer. E-mail: heiko.wittmer@vuw.ac.nz. scales due to their ability to move longer distances to utilize dispersed resources. Individuals, including those of less mobile species, can also maximize resource utilization by either remaining within the same general area or by returning to previously occupied areas (Merkle et al. 2014). These behaviors have been defined as site fidelity and are well documented across many vertebrate taxa (Greenwood 1980). The most prevalent explanation as to the evolutionary benefits of site fidelity focuses on familiarity (Piper 2011), as prior knowledge of the distribution of resources and refugia from predators plays an important role in effective habitat use (Switzer 1993) thus enhancing survival (Forrester et al. 2015) and 
reproductive success (Beletsky and Orians 1991). Studies across different spatial and temporal scales have also linked fidelity behavior to geographic structuring (Schaefer et al. 2000; van Beest et al. 2013) suggesting that fidelity at fine scales may affect demography and population dynamics (Morrison and Bolger 2012).

Dynamics and spatial distribution of animal populations at large spatial scales are also affected by dispersal (Taylor and Taylor 1977; Kendall et al. 2000). Depending on social organization and ecological conditions, individuals of different species may either establish home ranges within their natal area (i.e., philopatry) or may disperse and subsequently establish fidelity to a new area (Pusey 1987). Dispersal in mammals is predominately male-biased with immature males dispersing and females more often exhibiting philopatry (Greenwood 1980). Long-term familiarity and use of natal sites by females has been predicted to result in genetic structuring (Chesser 1991) and studies involving different taxonomic groups have linked sex-biased philopatry to fine-scale genetic structuring over successive generations (e.g., Storz 1999; Miller et al. 2010).

Due to their large plasticity in movement and dispersal strategies, both site fidelity and philopatry have received considerable attention in ungulates. Previous studies assessing site fidelity in ungulates have highlighted the importance of different temporal scales (Schaefer et al. 2000; van Beest et al. 2013) in explaining spatial patterns of clustering and range use with respect to seasonal variation in forage quality (Garrott et al. 1987; Pettorelli et al. 2007) and predation risk (Wittmer et al. 2006). Many studies, however, have relied on relatively short-term data to investigate the effects of fidelity on geographic structuring of ungulate populations at different spatial scales. Specifically, the generally short duration of telemetry studies may have limited our ability to link an understanding of site fidelity and population structuring to population dynamics over longer times scales. Studies on philopatry on the other hand have often used mitochondrial DNA (mtDNA) data to evaluate genetic structuring at broader temporal scales and distances beyond the dispersal abilities of the species (e.g., Purdue et al. 2000; Latch et al. 2014). Fidelity and philopatry, however, are intrinsically related and by acting simultaneously can cause fine-scale genetic structuring within populations even in continuous landscapes without physical barriers to movement (Nussey et al. 2005; Bolger et al. 2008). Thus, the combined use of telemetry and genetic data provide opportunities to increase our ability to understand population level consequences of site fidelity and philopatry and use such an understanding for developing effective conservation and management plans.

Black-tailed deer (Odocoileus hemionus columbianus) provide an ideal model to study the combined effect of site fidelity and philopatry on the spatial extent of population structuring. Their social structure is based on matriarchal lineages with groups composed of adult females and several generations of female offspring (Kie and Czech 2000). While previous studies have reported plasticity in range use and movement patterns (Geist 1981; Garrott et al. 1987), nonmigratory black-tailed deer occupy among the smallest reported home ranges of any medium sized ungulate (Taber and Dasmann 1957; Kelt and Van Vuren 2001). Together, these socio-behavioral attributes should predispose black-tailed deer to genetic structuring even among neighboring groups within a continuous population.

Our objectives were to quantify the extent of seasonal and annual site fidelity of female black-tailed deer in northern California, USA and to then estimate levels of philopatry to ultimately assess the combined effect of fidelity and philopatry on the genetic structuring of the population. To achieve our objectives, we used location data from 64 adult females fitted with global positioning system (GPS) collars between 2004 and 2013 and mtDNA haplotypes isolated from high quality tissue samples obtained from 48 individuals (i.e., 24 of the collared females and 24 unrelated fawns). The integrative approach of our study was particularly topical due to previously reported variability in vital rates at small spatial scales (Marescot et al. 2015) and thus the potential of demographic structuring of the population to affect meaningful assessments of its dynamics.

\section{METHODS}

\section{Study area}

Our study area was located within the Mendocino National Forest in the northwestern California Coast Ranges. The 1000 $\mathrm{km}^{2}$ study area comprised of 2 major ridges (FH7 and $\mathrm{Ml}$ ) and 3 main watersheds (Figure 1). Elevation in the study area ranges from approximately 250 to almost $2500 \mathrm{~m}$ above sea level, with moderately rolling terrain at lower elevations to steep and rugged terrain at higher elevations except on ridge tops. Climate is considered Mediterranean with mean daily temperatures ranging from $5{ }^{\circ} \mathrm{C}$ during winter to $17^{\circ} \mathrm{C}$ in summer (Mendocino Pass weather station; http://www.ncdc.noaa.gov/cdo-web). Temperatures reach extremes of $-11.5^{\circ} \mathrm{C}$ and $45.5^{\circ} \mathrm{C}$ in winter and summer, respectively. Mean annual precipitation over the study period averaged $148.8 \mathrm{~cm}$ with about $85 \%$ of the precipitation occurring from October through April. Snow cover was generally limited to elevations greater than $1000 \mathrm{~m}$ and was irregular, particularly during dry winters.

Major habitat types correlate with elevation and consist of (in order of increasing elevation): blue oak (Quercus douglasii) woodland, annual grassland, montane hardwood conifer, Douglas fir (Pseudotsuga menziesii), mixed chaparral, montane hardwood, ponderosa pine (Pinus ponderosa), Klamath mixed conifer, montane riparian, and montane chaparral (Mayer and Laudenslayer 1988). Black-tailed deer were the only resident ungulate and coexisted with an abundant and diverse predator community that included pumas (Puma concolor), American black bears (Ursus americanus), coyotes (Canis latrans), and bobcats (Lynx rufus). Female black-tailed deer spent summer and winter aggregated in habitats that provided both highquality and abundant forage (Wittmer et al. 2014; Lounsberry et al. 2015). Summer ranges were located on ridge tops where females also gave birth and winter ranges were in drainages at lower elevations. A majority of deer travelled the short distance (typically 5-10 $\mathrm{km}$ ) between their seasonal ranges over the course of 1-2 days.

\section{Capture and monitoring}

A total of 84 female black-tailed deer $\geq 1$-year old were captured over 2 separate time periods between September 2004 and August 2013 using free range darting. No deer were monitored between September 2008 and June 2009. One deer was captured and monitored during both time periods. Detailed capture and handling procedures are described in Casady and Allen (2013) and were approved by the Wildlife Investigations Laboratory of the California Department of Fish and Wildlife and the Institutional Animal Care and Use Committee at University of California, Davis (Protocols 15341 \& 16886). Captures occurred opportunistically, primarily from roads along the $\mathrm{FH} 7$ and $\mathrm{M} 1$ ridges at high elevations. All but 6 anesthetized deer had an incisiform canine tooth extracted for precise age determination based on cementum growth (Matson's Laboratory LLC, Missoula, MT); we used tooth eruption and wear 


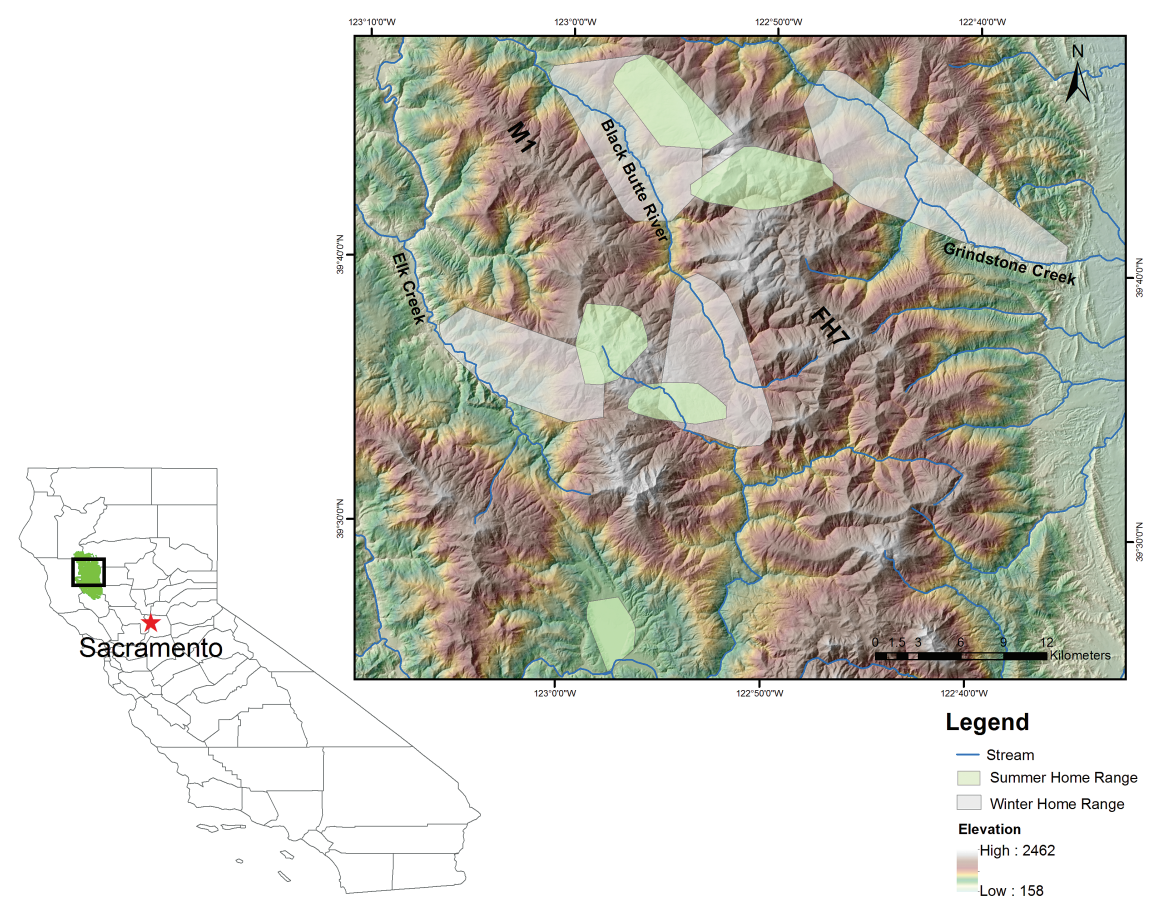

Figure 1

Location of the study area in California and intensive study area in the Mendocino National Forest covering 3 watersheds and 2 main ridges (Ml and FH7). Summer (5) and winter population ranges (4) were determined based on GPS location data of 65 adult female black-tailed deer monitored between 2004 and 2013.

patterns to determine age of individuals we did not extract teeth from. Deer were equipped with motion-sensitive, store-on-board GPS collars (Telonics, Mesa AZ and models 3300 and 4400M, Lotek Wireless, Inc., Newmarket, Ontario, Canada) that never exceeded $3 \%$ of bodyweight. Collars were programmed to obtain a GPS location every 1 to $5 \mathrm{~h}$ and were deployed for a maximum period of 2 years after which they automatically dropped off. Collars switched to a mortality signal after $4 \mathrm{~h}$ of inactivity facilitating recovery and identification of mortality causes (Marescot et al. 2015). Of the 84 female deer we captured, 3 died from capture related injuries and the collars of 4 individuals failed immediately. GPS location data from an additional 13 deer could not be retrieved leaving us with GPS location data from 64 individuals for our analyses.

\section{Home-range estimation and population structure}

Summer and winter home ranges of individual deer were estimated separately using the $95 \%$ local convex hull $(\mathrm{LoCoH})$ method applying the "minimum spurious hole covering" rule (Getz et al. 2007). Seasonal cut-off dates for each deer were identified from their GPS locations based on observed patterns in elevational movements and space use (Robert and Serrouya 2005). This allowed us to exclude GPS locations associated with elevational migrations from home range and fidelity analyses. Twelve deer did not show distinct elevational movements. For these deer locations were assigned to either summer or winter based on the median date of migration of other deer on the same seasonal range and year. We tested for differences in mean seasonal home range sizes between the 2 ridges using an analysis of variance.

Available location and home range data were also used to assign deer to seasonal population ranges following an approach described by Forrester et al. (2015). Specifically, individual deer were allocated to distinct summer and winter population ranges based on spatial gaps in the GPS data that were greater than twice the size of the average diameter of a seasonal home range and geographic features that may have discouraged movement between ranges (e.g., steep drainages). The extent of these distinct seasonal population ranges were then determined using 95\% minimum convex polygons from GPS locations of all collared deer within each seasonal range.

\section{Site fidelity analysis}

We based our assessment of site fidelity on interlocation distances within seasons and between years because approaches based on animal locations are generally considered more accurate than those based on home range overlap (e.g., Garrott et al. 1987; Conner and Leopold 2001). To avoid spurious statistical significance as a consequence of nonindependent GPS locations obtained for each individual deer, we subsampled our data by randomly choosing one location per week.

Within season, fidelity was estimated by calculating linear distances between all possible pairs of weekly locations for each collared individual within their individual seasonal ranges. To quantify between year fidelity to seasonal ranges, we used an approach similar to multiresponse permutation procedure (Mielke et al. 1976; Zimmerman et al. 1985) where linear distances between all locations within an individual's seasonal range were calculated pairwise across different years. If the mean within-year interlocation distances were equal or near equal to the mean interlocation distances between years, then the animal was considered to show a high degree of fidelity to its seasonal home range from 1 year to the next (Wittmer et al. 2006).

We examined variation in mean interlocation distances of female black-tailed deer as a function of temporal and spatial covariates using linear mixed effect (LME) models contained in the nlme package (Pinheiro et al. 2012). Interlocation distances were logtransformed and treated as the response variable. Explanatory variables included fidelity type (within year, between years) but also season (summer, winter) and area (FH7 ridge, $\mathrm{Ml}$ ridge). We included season and area as covariates in our site fidelity analysis 
because previous research highlighted both temporal and spatial variation in survival of deer in our population (Forrester et al. 2015; Marescot et al. 2015). All 3 explanatory variables and their first order interactions were included in the full model. To account for repeated measurements from the same individual, animal ID was included as a random intercept. The full model thus took the following form: Interlocation distances $\sim$ fidelity type + season + area + fidelity type $\times$ season + season $\times$ area + fidelity type $\times$ area + fidelity type $\times$ season $\times$ area $+(1 \mid$ ID). The statistical significance of each variable and their interactions was assessed by sequential backward elimination from the full model (Crawley 1993) followed by comparisons using likelihood ratio tests. Finally, we used least square regression models with the mean intra- and interyear location distances of individual deer as the dependent variable to test for the effect of age of female deer on fidelity.

We used Cox Proportional Hazards (CPH) models to assess the mortality risks associated with decreasing site fidelity (Cox 1972; Therneau and Grambsch 2000). The CPH framework allows the baseline mortality hazards to vary freely over time, thus removing any confounding effects due to seasonal or annual variation in mortality. As the seasonal ranges were spatially separated, we derived distinct models for each variable group. The number of deer monitored each year across our 8-year study period averaged $14.89 \pm 2.71$ (range from 4 to 29 ). We modeled their survival as a function of days since capture and estimated the time to "event" (i.e., mortality) for each individual that died $(n=28)$. We censored individuals upon collar failure or at the end of study $(n=36)$. We assessed the proportional hazard assumption (Winterstein et al. 2001) for our models by testing for nonzero slopes of Schoenfeld residuals (Schoenfeld 1982) and by inspecting plots of logarithmic estimates of the cumulative hazard functions (Cleves et al. 2004).

Unless otherwise noted, we assessed significance based on $\alpha=0.05$ and report variables as $\bar{x} \pm$ SE. All statistical analyses were performed in R (Version 0.98.1049) ( $\mathrm{R}$ Development Core Team 2012).

\section{Mitochondrial DNA and philopatry}

To assess whether female site fidelity behavior occurred over long enough periods of time (i.e., multigenerational) to translate to matrilineal population structure, we analyzed mitochondrial DNA, which is transferred along female lineages. Because females gave birth on high elevation summer ranges, we chose to look at genetic differences of individuals from the 2 main ridges where these ranges were located. Ridges were on average separated by $10.2 \pm 0.2 \mathrm{~km}$ $(\min =7.2 \mathrm{~km}, \max =13.9 \mathrm{~km}$; Figure 1$)$.

We used ear punches collected from 24 adult females during collaring as well as tissue samples from 24 unrelated fawns captured during the same time period (i.e., 2011-2012; Marescot et al. 2015). We extracted DNA from all 48 samples using Qiagen DNeasy blood and tissue kits (Qiagen Inc.) following manufacturer's instructions. We performed polymerase chain reaction (PCR) to amplify a 451 base pair (bp, including primers) portion of mitochondrial D loop using primers, HV1Deer-F (CTATTTAAACTATTCGCTGACG) and HV1Deer-R (GATCTAGGGGAGGGGATA). PCR were $23 \mu \mathrm{l}$ total volume and consisted of $2 \mu \mathrm{l}$ of DNA extract, $1 \mathrm{U}$ taq polymerase and other reagents at the following reaction concentrations: PGR buffer $(1 \times), \mathrm{MgCl}(2.5 \mathrm{mM})$, dNTPs $(0.2 \mathrm{mM})$, Bovine Serum Albumin $(0.1 \mathrm{mg} / \mathrm{ml})$, primers $(0.5 \mu \mathrm{M})$. The PCR cycle conditions were $94^{\circ} \mathrm{C}$ for $3 \mathrm{~min}, 33$ cycles of $94^{\circ} \mathrm{C}$ for $30 \mathrm{~s}, 50^{\circ} \mathrm{C}$ for $30 \mathrm{~s}$, and $72^{\circ} \mathrm{C}$ for $45 \mathrm{~s}$, followed by $10 \mathrm{~min}$ at $72^{\circ} \mathrm{C}$. We used dye terminator sequencing reactions for each PCR product from each primer using Applied Biosystems (Foster City, CA) reagents with products sequenced on an ABI 3730 capillary sequencer. After trimming primers (22 bp, $18 \mathrm{bp}$ ) and an additional $130 \mathrm{bp}$ (78 bp 5', 52 bp 3'), we obtained a 279 bp fragment that was unambiguously sequenced for all 48 individuals for analysis (Genbank Accession Nos. KX254554-KX254563).

To assess potential genetic structuring of females giving birth on different ridges, we constructed a median joining network of mitochondrial DNA haplotypes using the program Networks 4.613 (Bandelt et al. 1999). We estimated haplotype and nucleotide diversity in DNAsp (Librado and Rozas 2009) and tested for population genetic subdivision using the frequency-based $F_{\mathrm{ST}}$ approach implemented in Arlequin 3.5 (Excoffier and Lischer 2010). The value of $F_{\mathrm{ST}}$ indicates the magnitude of genetic structure, with $F_{\mathrm{ST}}=0$ (the null hypothesis) implying no genetic structure and $F_{\mathrm{ST}}>0$ implying impeded gene flow between ridges. In theory, $F_{\mathrm{ST}}=1 /\left(2 m \mathcal{N}_{f}+1\right)$, implying that exchange of a single female migrant $\left(m \mathcal{N}_{f}\right)$ per generation corresponds to $F_{\mathrm{ST}}=0.33$.

\section{RESULTS}

\section{Home ranges and population structure based on telemetry data}

Average adult female home range sizes varied between the M1 and FH7 ridges during both summer $\left(\mathrm{Ml}=0.98 \mathrm{~km}^{2} \pm 0.09\right.$ vs. FH7 $\left.=0.56 \mathrm{~km}^{2} \pm 0.05 ; F_{2,51}=9.179, P=0.004\right)$ and winter $\left(\mathrm{M} 1=1.19 \mathrm{~km}^{2} \pm 0.17\right.$ vs. $\mathrm{FH} 7=0.79 \mathrm{~km}^{2} \pm 0.10 ; F_{2,51}=2.247$, $P=0.036)$. In general, individuals associated with the M1 ridge had between $50 \%$ and $70 \%$ larger seasonal home ranges than individuals associated with the $\mathrm{FH} 7$ ridge. Based on available telemetry data, collared female deer associated with 1 of 5 distinct summer ranges $\left(\min =12.0 \mathrm{~km}^{2} ; \max =30.7 \mathrm{~km}^{2}\right)$ and 1 of 4 distinct winter ranges $\left(\min =55.2 \mathrm{~km}^{2} ; \max =100.5 \mathrm{~km}^{2}\right)($ Figure 1$)$.

\section{Site fidelity}

Annual sample sizes of deer and locations used to estimate fidelity within and between seasons are shown in Table 1. Our linear mixed effect model showed no statistically significant interaction or main effect of fidelity type, season, or area on mean interlocation distances of individual deer (Table 2). None of the explanatory variables improved model fit (Table 3). Differences in mean

Table 1

Number of individuals $\left(n_{\mathrm{A}}\right)$ and number of weekly GPS locations $\left(n_{\mathrm{L}}\right)$ of black-tailed deer by year, season, and area (M1 or FH7 ridge) between 2004 and 2014 in the Mendocino National Forest, California

\begin{tabular}{|c|c|c|c|c|c|c|c|c|}
\hline \multirow[t]{3}{*}{ Year } & \multicolumn{4}{|c|}{ Summer } & \multicolumn{4}{|c|}{ Winter } \\
\hline & \multicolumn{2}{|c|}{ M1 } & \multicolumn{2}{|c|}{ FH7 } & \multicolumn{2}{|c|}{ M1 } & \multicolumn{2}{|c|}{ FH7 } \\
\hline & $n_{\mathrm{A}}$ & $n_{\mathrm{L}}$ & $n_{\mathrm{A}}$ & $n_{\mathrm{L}}$ & $n_{\mathrm{A}}$ & $n_{\mathrm{L}}$ & $n_{\mathrm{A}}$ & $n_{\mathrm{L}}$ \\
\hline 2004-2005 & 4 & 39 & - & - & 5 & 51 & - & - \\
\hline 2005-2006 & 9 & 209 & - & - & 5 & 152 & - & - \\
\hline $2006-2007$ & 5 & 119 & - & - & 5 & 133 & - & - \\
\hline 2007-2008 & 6 & 130 & - & - & - & - & - & - \\
\hline 2008-2009 & - & - & 4 & 51 & - & - & 3 & 76 \\
\hline 2009-2010 & 6 & 79 & 3 & 39 & 5 & 88 & 2 & 64 \\
\hline 2010-2011 & 4 & 83 & 6 & 98 & 2 & 44 & 3 & 66 \\
\hline $2011-2012$ & 5 & 80 & 3 & 103 & 4 & 101 & 3 & 54 \\
\hline 2012-2013 & 8 & 93 & 12 & 215 & 5 & 115 & 11 & 287 \\
\hline 2013-2014 & 3 & 50 & 11 & 197 & - & - & - & - \\
\hline
\end{tabular}


interlocation distances among individuals (Supplementary Figure S1) explained $13 \%$ of the observed variation. We also found no effect of age on within and between year fidelity to seasonal ranges (summer within: $F_{1,49}=0.097, P=0.757$; summer between: $F_{1,31}=0.721, P=0.402$; winter within: $F_{1,42}=1.231, P=0.274$; winter between: $\left.F_{1,8}=0.152, P=0.707\right)$. The lack of differences in interlocation distances within and between years during both summer and winter indicated that female deer returned to the same areas in consecutive years (Table 4).

Annual survival probabilities for female deer averaged $0.76 \pm 0.03$ across all years. Fidelity to seasonal ranges appeared to be correlated with mortality risk. We found that increases in mean interlocation distances between consecutive summers significantly increased the risk of mortality $(\beta=0.448, P=0.046)$. Specifically, summer survival probabilities of deer averaged $0.92 \pm 0.07$ for individuals with interlocation distances of $\leq 1 \mathrm{~km}$ between consecutive summers. For every additional kilometer in interlocation distances between consecutive summers, survival decreased by $56.5 \%$ (Figure 2). The nonsignificant Schoenfeld residuals $(\sigma=-0.154, P=0.690)$ suggested that the assumptions for the model were adequately met. No other significant effects on mortality were apparent from our data.

\section{Philopatry and genetic population structure}

We observed a total of 10 haplotypes, corresponding to a gene diversity of $0.75 \pm 0.06$ and a nucleotide diversity of $0.013 \pm 0.002$. The haplotype diversity was $48 \%$ higher on the $\mathrm{M} 1$ ridge $(0.89 \pm 0.04, n=19)$ than the $\mathrm{FH} 7$ ridge $(0.43 \pm 0.11$, $n=29$ ). However, the nucleotide diversity was similar between the ridges $(\mathrm{Ml}=0.013 \pm 0.002 ; \mathrm{FH} 7=0.010 \pm 0.004)$. Overall, haplotype sharing was low (Figure 3), corresponding to a marked genetic subdivision between the $\mathrm{M} 1$ and $\mathrm{FH} 7$ ridges $\left(F_{\mathrm{ST}}=0.36\right.$, $P<0.001)$. By rearranging the formula $F_{\mathrm{ST}} \approx 1 /\left(2 m \mathcal{N}_{f}+1\right)$ where $m \mathcal{N}_{f}$ is the number of female migrants per generation, we obtained an estimate of $\approx 0.89$ female deer moving between ridges per generation. The haplotype network revealed visible genetic structuring between $\mathrm{M} 1$ and $\mathrm{FH} 7$ ridges. Of the 10 total haplotypes, 5 were restricted to $\mathrm{M} 1,2$ to $\mathrm{FH} 7$, and the remaining 3 haplotypes were shared across both localities (Figure 3).

\section{DISCUSSION}

Our approach differed from most previous studies in that we combined detailed spatial data from GPS collared individuals with mtDNA samples to simultaneously assess the effects of fidelity and philopatry. Results based on our telemetry data revealed very small seasonal home ranges together with high site fidelity in female black-tailed deer, which did not vary spatially (i.e., between ridges) or with age. Plasticity in movement behavior among individuals was low but linked to improved survival of adult female deer with higher site fidelity, demonstrating a possible mechanism to explain the prevalence of female philopatry in our population. Results from mtDNA sequencing revealed a range of locality specific haplotypes with low level of interpopulation mixing and very high genetic differentiation $\left(F_{\mathrm{ST}}>0.30\right)$ between the $\mathrm{M} 1$ and $\mathrm{FH} 7$ ridges even though wintering ranges where mating occurred were separated by as little as $4 \mathrm{~km}$. The high genetic differentiation we discovered indicated multigenerational philopatric behavior in the matrilineage. Combined, these findings improve our understanding of the short and long-term population level consequences of animal movements and fidelity in species with sex-biased dispersal.

The high $F_{\mathrm{ST}}$ value and low level of shared haplotypes observed among individuals on the different ridges was indicative of population subdivision and genetic drift, which can over time lead to population isolation and thus locally disjunct subpopulations (Greenwood 1980; Robertson and Cooke 1999). As measures of $F_{\mathrm{ST}}$ are based on an idealized population at equilibrium between the opposing forces of genetic drift, mutation and migration, the very high $F_{\mathrm{ST}}$ estimate suggests that genetic divergence and therefore philopatry of females was not limited to just a few generations but over a relatively longer time scale. Populations are said to be isolated if the dynamics are entirely dependent on local birth and death rates and not by migration events (Turchin 2003). Isolation can either be genetic (no immigrants of either gender), demographic (immigrants of one gender only), or both (local isolation). Although genetic differentiation among individuals on the different ridges was high, it is unlikely that the population was genetically isolated as 1) only female deer and, more importantly, maternally inherited markers, were sampled in this study, 2) male black-tailed deer were continuously distributed throughout the study area, and 3) females from both ridges seasonally migrated to the same low elevation winter ranges where mating occurred and thus shared the same male mating pool. Rather, it appears that black-tailed deer may be experiencing small-scale demographic isolation due to strong philopatry, where, similar to white-tailed deer (O. viginianus; Porter et al. 1991), females are predominantly recruited into existing family groups. This isolation persists despite the lack of barriers to movement in our study area. Identifying such demographic isolation is important, given that population dynamics in polygynous cervids including black-tailed deer are typically based on estimates of vital rates of females only (Gaillard et al. 2000; Forrester and Wittmer 2013).

\section{Table 2}

\section{Variation in mean interlocation distances of female black-tailed deer as a function of fidelity type (within and between years), season (summer and winter), and area (FH7 vs. M1 ridge) based on LME models}

\begin{tabular}{|c|c|c|c|c|c|c|}
\hline Model & df & $\mathrm{AIC}$ & Log likelihood & Test & L.Ratio & $p$ value \\
\hline 1) Null model & 5 & 210408.9 & -105199.4 & & & \\
\hline 2) Fidelity Type & 6 & 210409.5 & -105198.8 & 1 vs. 2 & 1.36 & 0.243 \\
\hline 3) Season & 7 & 210411.4 & -105198.7 & 2 vs. 3 & 0.12 & 0.730 \\
\hline 4) Area & 8 & 210411.3 & -105197.7 & 3 vs. 4 & 2.03 & 0.154 \\
\hline 5) Fidelity x Season & 9 & 210413.0 & -105197.5 & 4 vs. 5 & 0.40 & 0.528 \\
\hline 6) Area x Season & 10 & 210413.2 & -105196.6 & 5 vs. 6 & 1.73 & 0.189 \\
\hline 7) Fidelity type $x$ Area & 11 & 210415.2 & -105196.6 & 6 vs. 7 & 0.01 & 0.944 \\
\hline 8) Full Model & 12 & 210417.0 & -105196.5 & 7 vs. 8 & 0.20 & 0.653 \\
\hline
\end{tabular}

The statistical significance of each variable and their interactions was assessed by backward elimination from the full model. Model comparison based on Akaike Information Criterion (AIC), log likelihood and outcomes likelihood ratio test. 
Table 3

Summary statistics full model conducted to assess the significance of main (fixed) effects and interactions on mean interlocation distances (log-transformed) of female black-tailed deer.

\begin{tabular}{lrrrrr} 
& Value & SE & df & $t$ value & $P$ value \\
\hline Fidelity type & -0.12 & 0.21 & 31 & -0.57 & 0.571 \\
Season & -0.12 & 0.37 & 49 & -0.33 & 0.746 \\
Area & 0.06 & 0.24 & 50 & 0.25 & 0.806 \\
Fidelity type $\times$ Season & -0.11 & 0.42 & 49 & -0.27 & 0.789 \\
Fidelity Type $\times$ Area & -0.03 & 0.29 & 31 & -0.09 & 0.932 \\
Season $\times$ Area & 0.40 & 0.48 & 49 & 0.82 & 0.414 \\
Fidelity type $\times$ Season $\times$ Area & -0.08 & 0.55 & 49 & -0.13 & 0.892 \\
\end{tabular}

Table 4

Mean seasonal interlocation distances for female black-tailed deer within and between years and their corresponding sample $\operatorname{sizes}\left(n_{\mathbf{A}}\right)$

\begin{tabular}{llrl} 
Season & Group & $n_{\mathrm{A}}$ & Mean distance $(\mathrm{km})$ \\
\hline Summer & Within & 51 & $0.81 \pm 0.12$ \\
& Between & 33 & $0.90 \pm 0.21$ \\
Winter & Within & 44 & $0.65 \pm 0.08$ \\
& Between & 9 & $1.01 \pm 0.23$ \\
\hline
\end{tabular}

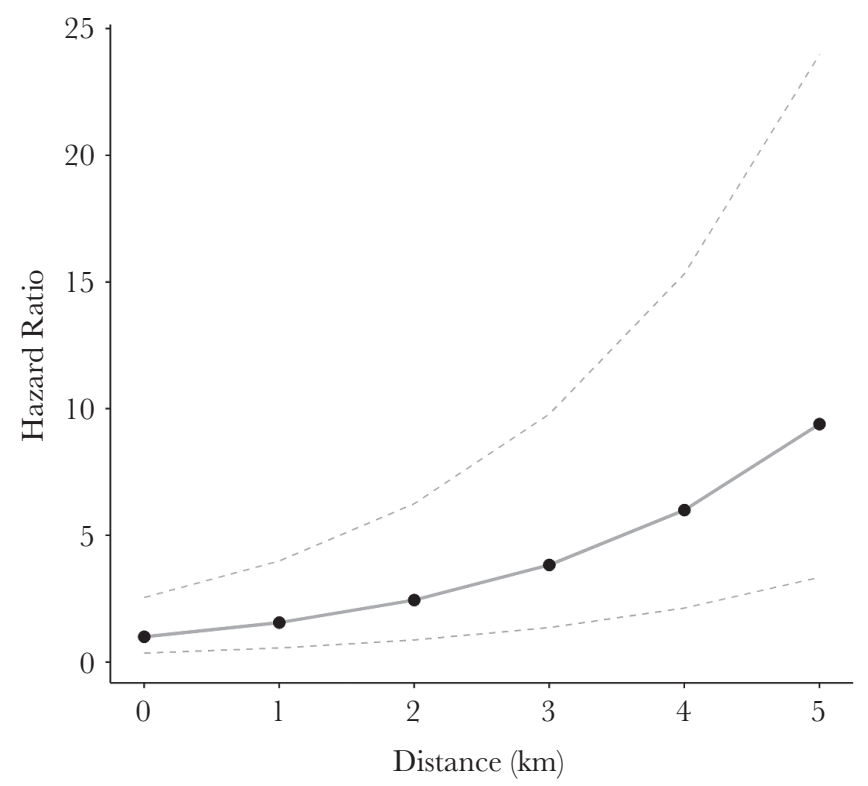

Figure 2

Estimated Hazard ratio with 95\% confidence intervals of female blacktailed deer in the Mendocino National Forest as a function of between-year interlocation distances during summer.

Low movement rates combined with high fidelity to seasonal ranges across successive years resulted in extremely small home ranges for our study animals. Mean seasonal home range sizes of $0.71 \mathrm{~km}^{2}$ in summer and $0.99 \mathrm{~km}^{2}$ in winter were smaller than previously reported home range estimates for black-tailed deer (Geist 1981; Garrott et al. 1987) and most other ungulates of comparable size (Kelt and Van Vuren 2001). The slightly larger size of winter ranges is consistent with previous findings (Lesage et al. 2000; Wittmer et al. 2006) and likely a

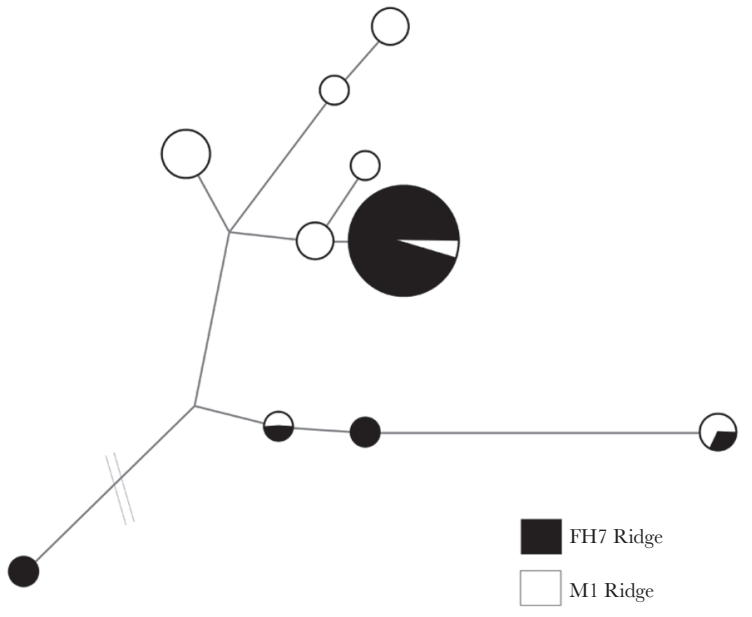

Figure 3

Mitochondrial haplotype network illustrating the low sharing of haplotypes between ridges. Based on 48 individuals ( 24 adult females and 24 unrelated fawns) captured on the FH7 $(n=29)$ and M1 $(n=19)$ ridges, Mendocino National Forest, 2011-2012.

consequence of either reduced availability or quality of forage during the colder months or increased mobility associated with the mating season. Larger seasonal home ranges on the M1 ridge may have been related to forage availability and population density. For example, results from vegetation surveys indicated lower forage availability and quality on the M1 ridge (Wittmer et al. 2014). At the same time, density of female black-tailed deer was lower on the M1 than the FH7 ridge (Lounsberry et al. 2015) and smaller home range sizes have been hypothesized to reduce competition at high densities in cervids (Larson et al. 1978; Lesage et al. 2000).

Importantly, we found that site fidelity was positively linked to increased survival in female black-tailed deer, a possible mechanism explaining high levels of philopatry. Evidence for a link between movement behavior including site fidelity and survival is still rare (Morales et al. 2010) and might have been due to benefits associated with site familiarity (Piper 2011). For example, individuals living within small, familiar home ranges have been shown to reduce the time they spend searching for forage and thus encounters with predators (Wolf et al. 2009). In our system, annual survival probabilities of adult female deer were low (0.76) compared to previous estimates reported across the distribution of mule and black-tailed deer $(0.84$; Forrester and Wittmer 2013). In addition, predation from pumas accounted for $86 \%$ of known mortalities of adult females in our study area and primarily occurred during summer (Allen et al. 2014; Marescot et al. 2015). Returning to small but highly familiar home ranges during consecutive summers thus apparently lowered mortality risks including from predation, highlighting fitness benefits of both familiarity and reduced movements. This finding also matches earlier research that found a higher predation risk for female deer in our study when they strayed outside their 95\% summer home ranges (Forrester et al. 2015).

Prevalence of philopatry and fidelity is expected to vary with population density and trends. Specifically, individuals should be more compelled to disperse when the costs of competition for forage at high population density outweigh the fitness benefits of staying put (Matthysen 2005; Morales et al. 2010). Site fidelity behavior 
is expected to be more pronounced at low population densities and in declining populations when associated interference competition is low (Merkle et al. 2015). However, we found evidence for philopatry over multiple generations and high site fidelity despite high blacktailed deer densities on summer ranges in our study area (male density ranged from $7.80 \pm 2.60$ to $18.20 \pm 6.88$ per $\mathrm{km}^{2}$, female density ranged from $24.58 \pm 3.48$ to $52.45 \pm 10.75$ per km²; Lounsberry et al. 2015). These results suggest that benefits of philopatry and site fidelity seem to have outweighed costs from competition with conspecifics. Over time, this may lead to high local densities and potential population increases beyond carrying capacity, increasing the likelihood of a population decline due to over-utilization of resources (Leopold et al. 1947; Forrester and Wittmer 2013; Merkle et al. 2015). Demographic recovery following population declines will then either depend on immigrants from expanding populations in the vicinity that did not suffer a decline or on local births rates (Porter et al. 1991; Duckworth 2008; Bitume et al. 2013). Our observed pattern of genetic structuring hints at a trend of historic demographic fluctuations with infrequent immigration. If true, then local birth rates will be more important than founding females for reestablishing populations with high philopatry that experience population declines.

We have shown that strong site fidelity and sex-biased philopatry causes population structuring and likely dynamics at a much finer scale than previously established in black-tailed deer or other species with strong matrilineal groups. Low maternal gene flow, as evidenced by the occurrence of few representative mtDNA haplotypes on each ridge, reveals that high levels of philopatry and low female movement between adjacent family groups can lead to demographic isolation with potentially localized vital rates (Monteith et al. 2014; Marescot et al. 2015) and result in small-scale differences in estimates of population growth. In populations with high site fidelity and philopatry among females, consideration should thus be given to matrilineal groups as the basic unit of genetic structuring and the potential to effect their conservation and management.

\section{SUPPLEMENTARY MATERIAL}

Supplementary data are available at Behavioral Ecology online.

\section{FUNDING}

Funding was provided by the California Department of Fish and Wildlife (\#P0880013) and the California Deer Association (\#08001495, \#001-10, \#011-11). S.B. and T.D.F. were supported by a Victoria University of Wellington Doctoral Scholarship and a Robert and Patricia Switzer Foundation Environmental Fellowship, respectively.

We are indebted to the numerous students and wildlife professionals who helped with data collection in the field. J.-M. Gaillard and an anonymous reviewer provided many helpful comments on a previous version of this manuscript.

Data accessibility: Analyses reported in this article can be reproduced using data provided by Bose et al. (2017).

Handling editor: Francisco Garcia-Gonzalez

\section{REFERENCES}

Allen ML, Elbroch LM, Casady DS, Wittmer HU. 2014. Seasonal variation in the feeding ecology of pumas (Puma concolor) in northern California. Can J Zool. 92:397-403.
Bandelt HJ, Forster P, Röhl A. 1999. Median-joining networks for inferring intraspecific phylogenies. Mol Biol Evol. 16:37-48.

Beletsky LD, Orians GH. 1991. Effects of breeding experience and familiarity on site fidelity in female red-winged blackbirds. Ecology 72:787-796.

Bitume EV, Bonte D, Ronce O, Bach F, Flaven E, Olivieri I, Nieberding CM. 2013. Density and genetic relatedness increase dispersal distance in a subsocial organism. Ecol Lett. 16:430-437.

Bolger DT, Newmark WD, Morrison TA, Doak DF. 2008. The need for integrative approaches to understand and conserve migratory ungulates. Ecol Lett. 11:63-77.

Bose S, Forrester TD, Brazeal JL, Sacks BN, Casady DS, Wittmer HU. 2017. Data from: implications of fidelity and philopatry for the population structure of female black-tailed deer. Dryad Digital Repository. http://dx.doi.org/10.5061/dryad.k029v.2

Casady DS, Allen ML. 2013. Handling adjustments to reduce chemical capture-related mortality in black-tailed deer. Calif Fish Game 99:104-109.

Chesser RK. 1991. Influence of gene flow and breeding tactics on gene diversity within populations. Genetics. 129:573-583.

Cleves MA, Gould WW, Gutierrez RG. 2004. An introduction to survival analysis using Stata, revised edition. College Station (TX): Stata Press.

Clutton-Brock TH, Coulson T. 2002. Comparative ungulate dynamics: the devil is in the detail. Philos Trans R Soc Lond B Biol Sci. 357:1285-1298.

Coltman DW, Pilkington JG, Pemberton JM. 2003. Fine-scale genetic structure in a free-living ungulate population. Mol Ecol. 12:733-742.

Conner LM, Leopold BD. 2001. A Euclidean distance metric to index dispersion from radiotelemetry data. Wildl Soc B. 29:783-786.

Cox DR. 1972. Regression models and life tables. J R Stat Soc. 34:187-220.

Crawley MJ. 1993. Glim for ecologists. Oxford (UK): Blackwell Science.

Duckworth RA. 2008. Adaptive dispersal strategies and the dynamics of a range expansion. Am Nat. 172:S4-S17.

Excoffier L, Lischer HE. 2010. Arlequin suite ver 3.5: a new series of programs to perform population genetics analyses under Linux and Windows. Mol Ecol Resour. 10:564-567.

Forrester TD, Wittmer HU. 2013. A review of the population dynamics of mule deer and black-tailed deer Odocoileus hemionus in North America. Mammal Rev. 43:292-308.

Forrester TD, Casady DS, Wittmer HU. 2015. Home sweet home: fitness consequences of site familiarity in female black-tailed deer. Behav Ecol Sociobiol. 69:603-612.

Gaillard J-M, Festa-Bianchet M, Yoccoz NG, Loison A, Toigo C. 2000. Temporal variation in fitness components and population dynamics of large herbivores. Annu Rev Ecol Syst. 31:367-393.

Garrott RA, White GC, Bartmann RM, Carpenter LH, Alldredge AW. 1987. Movements of female mule deer in northwest Colorado. J Wildl Manage. 51:634-643.

Geist V. 1981. Behavior: adaptive strategies in mule deer. In: Wallmo OC, editor. Mule and black-tailed deer of North America. Lincoln (NE): University of Nebraska Press. p. 157-223.

Getz WM, Fortmann-Roe S, Cross PC, Lyons AJ, Ryan SJ, Wilmers CC. 2007. LoCoH: nonparameteric kernel methods for constructing home ranges and utilization distributions. PLoS One. 2:e207.

Greenwood PJ. 1980. Mating systems, philopatry and dispersal in birds and mammals. Anim Behav. 28:1140-1162.

Kelt DA, Van Vuren DH. 2001. The ecology and macroecology of mammalian home range area. Am Nat. 157:637-645.

Kendall BE, Bjørnstad ON, Bascompte J, Keitt TH, Fagan WF. 2000. Dispersal, environmental correlation, and spatial synchrony in population dynamics. Am Nat. 155:628-636.

Kie JG, Czech B. 2000. Mule and black-tailed deer. In: Demarais S, Krausman PR, editors. Ecology and management of large mammals in North America. Upper Saddle River (NJ): Prentice Hall. p. 629-657.

Larson TJ, Rongstad OJ, Terbilcox FW. 1978. Movement and habitat use of white-tailed deer in southcentral Wisconsin. J Wildl Manage. 42:113-117.

Latch EK, Reding DM, Heffelfinger JR, Alcalá-Galván CH, Rhodes OE Jr. 2014. Range-wide analysis of genetic structure in a widespread, highly mobile species (Odocoileus hemionus) reveals the importance of historical biogeography. Mol Ecol. 23:3171-3190.

Leopold A, Sowls LK, Spencer DL. 1947. A survey of over-populated deer ranges in the United States. J Wildl Manage. 11:162-177.

Lesage L, Crête M, Huot J, Dumont A, Ouellet JP. 2000. Seasonal home range size and philopatry in two northern white-tailed deer populations. Can J Zool. 78:1930-1940. 
Librado P, Rozas J. 2009. DnaSP v5: a software for comprehensive analysis of DNA polymorphism data. Bioinformatics. 25:1451-1452.

Lounsberry ZT, Forrester TD, Olegario MT, Brazeal JL, Wittmer HU, Sacks BN. 2015. Estimating sex-specific abundance in fawning areas of a high-density Columbian black-tailed deer population using fecal DNA. J Wildl Manage. 79:39-49.

Marescot L, Forrester TD, Casady DS, Wittmer HU. 2015. Using multistate capture-mark-recapture models to quantify effects of predation on age-specific survival and population growth in black-tailed deer. Pop Ecol. 57:185-197.

Matthysen E. 2005. Density-dependent dispersal in birds and mammals. Ecography 28:403-416.

Mayer KE, Laudenslayer WF. 1988. A guide to wildlife habitats of California. Sacramento (CA): California Department of Forestry and Fire Protection.

Merkle JA, Fortin D, Morales JM. 2014. A memory-based foraging tactic reveals an adaptive mechanism for restricted space use. Ecol Lett. 17:924-931.

Merkle JA, Cherry SG, Fortin D. 2015. Bison distribution under conflicting foraging strategies: site fidelity vs. energy maximization. Ecology. 96:1793-1801.

Mielke Jr PW, Berry KJ, Johnson ES. 1976. Multi-response permutation procedures for a priori classifications. Commun Stat A-Theor. 5:1409-1424.

Miller BF, De Young RW, Campbell TA, Laseter BR, Ford WM, Miller KV. 2010. Fine-scale genetic and social structuring in a central Appalachian white-tailed deer herd. J Mammal. 91:681-689.

Monteith KL, Bleich VC, Stephenson TR, Pierce BM, Conner MM, Kie JG, Bowyer RT. 2014. Life-history characteristics of mule deer: effects of nutrition in a variable environment. Wildl Monogr. 186:1-62.

Morales JM, Moorcroft PR, Matthiopoulos J, Frair JL, Kie JG, Powell RA, Merrill EH, Haydon DT. 2010. Building the bridge between animal movement and population dynamics. Philos Trans R Soc Lond B Biol Sci. 365:2289-2301.

Morrison TA, Bolger DT. 2012. Wet season range fidelity in a tropical migratory ungulate. J Anim Ecol. 81:543-552.

Nussey DH, Coltman DW, Coulson T, Kruuk LE, Donald A, Morris SJ, Clutton-Brock TH, Pemberton J. 2005. Rapidly declining fine-scale spatial genetic structure in female red deer. Mol Ecol. 14:3395-3405.

Pettorelli N, Pelletier F, Von Hardenberg A, Festa-Bianchet M, Côté SD. 2007. Early onset of vegetation growth vs. rapid green-up: impacts on juvenile mountain ungulates. Ecology 88:381-390.

Pinheiro J, Bates D, DebRoy S, Sarkar D; the R Development Core Team. 2012. nlme: linear and nonlinear mixed effects models. R package version 3.1-103. Vienna: R Foundation for Statistical Computing.

Piper WH. 2011. Making habitat selection more "familiar": a review. Behav Ecol Sociobiol. 65:1329-1351.

Porter WF, Mathews NE, Underwood HB, Sage Jr. RW, Behrend DF. 1991. Social organization in deer: implications for localized management. Environ Manage. 15:809-814.

Purdue JR, Smith MH, Patton JC. 2000. Female philopatry and extreme spatial genetic heterogeneity in white-tailed deer. J Mammal. 81:179-185.
Pusey AE. 1987. Sex-biased dispersal and inbreeding avoidance in birds and mammals. Trends Ecol Evol. 2:295-299.

R Development Core Team 2012. R: a language and environment for statistical computing. Vienna (Austria): R Foundation for Statistical Computing. http://www.R project.org/.

Robert GD, Serrouya R. 2005. Mule deer seasonal movements and multiscale resource selection using global positioning system radiotelemetry. J Mammal. 86:736-44.

Robertson GJ, Cooke F. 1999. Winter philopatry in migratory waterfowl. Auk 116:20-34.

Schaefer JA, Bergman CM, Luttich SN. 2000. Site fidelity of female caribou at multiple spatial scales. Landscape Ecol. 15:731-739.

Schoenfeld D. 1982. Partial residuals for the proportional hazards regression model. Biometrika 69:239-241.

Storz JF. 1999. Genetic consequences of mammalian social structure. J Mammal. 80:553-569.

Switzer PV. 1993. Site fidelity in predictable and unpredictable habitats. Evol Ecol. 7:533-555.

Taber RD, Dasmann RF. 1957. The dynamics of three natural populations of the deer Odocoileus hemionus columbianus. Ecology 38:233-246.

Taylor LR, Taylor RA. 1977. Aggregation, migration and population mechanics. Nature. 265:415-421.

Therneau TM, Grambsch PM. 2000. Modeling survival data: extending the Cox model. New York: Springer-Verlag.

Turchin P. 2003. Complex population dynamics: a theoretical/empirical synthesis (MPB-35). Princeton (NJ): Princeton University Press.

Turner MG. 1989. Landscape ecology: the effect of pattern on process. Annu Rev Ecol Syst. 20:171-197.

van Beest FM, Vander Wal E, Stronen AV, Paquet PC, Brook RK. 2013. Temporal variation in site fidelity: scale-dependent effects of forage abundance and predation risk in a non-migratory large herbivore. Oecologia. 173:409-420.

Winterstein SR, Pollock KH, Bunck CM. 2001. Analysis of survival data from radio-telemetry studies. In: Millspaugh JJ, Marzluff JM, editors. Radio tracking and animal populations. San Diego (CA): Academic Press. p. 351-380.

Wittmer HU, McLellan BN, Hovey FW. 2006. Factors influencing variation in site fidelity of woodland caribou (Rangifer tarandus caribou) in southeastern British Columbia. Can J Zool. 84:537-545.

Wittmer HU, Forrester TD, Allen ML, Marescot L, Casady DS. 2014 Black-tailed deer population assessment in the Mendocino National Forest, California. Report to the California Department of Fish and Wildlife. https://www.researchgate.net/publication/273449867_Blacktailed_Deer_Population_Assessment_In_The_Mendocino_National_ Forest_California_2009_-_2013.

Wolf M, Frair J, Merrill E, Turchin P. 2009. The attraction of the known: the importance of spatial familiarity in habitat selection in wapiti Cervus elaphus. Ecography 32:401-10.

Zimmerman GM, Goetz H, Mielke Jr PW 1985. Use of an improved statistical method for group comparisons to study effects of prairie fire. Ecology 66:606-611. 